\title{
Wall Stabilization Action on MHD Instabilities
}
D. Berger
L. C. Bernard
R. Gruber
F. Troyon 


\section{DISCLAIMER}

This report was prepared as an account of work sponsored by an agency of the United States Government. Neither the United States Government nor any agency Thereof, nor any of their employees, makes any warranty, express or implied, or assumes any legal liability or responsibility for the accuracy, completeness, or usefulness of any information, apparatus, product, or process disclosed, or represents that its use would not infringe privately owned rights. Reference herein to any specific commercial product, process, or service by trade name, trademark, manufacturer, or otherwise does not necessarily constitute or imply its endorsement, recommendation, or favoring by the United States Government or any agency thereof. The views and opinions of authors expressed herein do not necessarily state or reflect those of the United States Government or any agency thereof. 


\section{DISCLAIMER}

Portions of this document may be illegible in electronic image products. Images are produced from the best available original document. 
Printed in the United States of America. Available from National Technical Information Service

U.S. Department of Commerce

5285 Port Royal Road, Springfield, Virginia 22161

Price: Printed Copy $\$ 4.00$; Microfiche $\$ 3.00$

This report was prepared as an account of work sponsored by an agency of the United States Government. Neither the United States Government nor any agency thereof, nor any of their employees, contractors, subcontractors, or their employees, makes any warranty, express or implied, nor assumes any legal liability or responsibility for any third party's use or the results of such use of any information, apparatus, product or process disclosed in this report, nor represents that its use by such third party would not infringe privately owned rights. 
ORNL/TM-6219

Dist. Category UC-20g

Contract No. W-7405-eng-26

FUSION ENERGY DIVISION

WALL STABILIZATION ACTION ON MHD INSTABILITIES

D. Berger

Oak Ridge National Laboratory, Oak Ridge, Tennessee 37830

L. C. Bernard

General Atomic Company, San Diego, California 92138

R. Gruber and F. Troyon

CRPP, Lausanne, Switzerland

Date Published - April, 1978

This report was prepared as an accoutit of work sponsored by the United States Govemment. Neither the United States nor the United States Department of Energy, nor any of their employees, nor any of their contractors, subcontractors, or their employees, makes any watranty, express or imptied, or assumes any legal liabillty or raspsnkibility for the atuuraoy, enmpletusess or ussfulness of any information, apparatus, product or process disclosed, or represents that is use woutd not infringe privately owned rights.

NOTICE This document contains information of a preliminary nature.

It is subject to revision or correction and therefore does not represent a final report.

Prepared by the

OAK RIDGE NATIONAL LABORATORY

Oak Ridge, Tennessee 37830

operated by

UNION CARBIDE CORPORATION

for the

DEPARTMENT OF ENERGY 


\section{THIS PAGE}

\section{WAS INTENTIONALLY LEFT BLANK}


ABSTRACT . . . . . . . . . . . . . . . . . . . 1

1. INTRODUCTION . . . . . . . . . . . . . . . 2

2. EQUILIBRIUM PARAMETERS ................ 3

3. RESULTS . . . . . . . . . . . . . . . . . . 4

3.1 Axisymmetric Mode . . . . . . . . . . . . 4

$3.2 \mathrm{~N}=1, \mathrm{~N}=2$.................. . . . 4

$3.3 \mathrm{q}_{\mathrm{s}}$ Dependence . . . . . . . . . . . . . . . . . 5

4. CONCLUSION . . . . . . . . . . . . . . . . 6

REFERENCES ....................... 7 


\section{ABSTRACT}

This paper presents the effects of a perfectly conducting wall on the MHD stability behavior of high beta tokamak equilibria. Toroidal wave numbers $N=0,1$, and 2 have been considered. For a reasonable wall-plasma distance, a range of stable operation corresponding to beta values greater than $10 \%$ has been found. 


\section{INTRODUCTION}

The FCT concept ${ }^{l}$ has considerably changed our understanding of tokamak limitations. Equilibria characterized by an average beta up to $40 \%$ have been obtained ${ }^{2}$, well above the value in current experiments. If such equilibria are stable against gross instabilities, the impact on the design of an electric power reactor is considerable, decreasing its size by a factor of three and increasing its output power by a factor of ten. Magnetohydrodynamic (MHD) stability computations on ballooning modes have shown critical beta values up to $10 \%$ for equilibria characterized by flat current profiles. ${ }^{3,4}$ To fulfill this condition, the gradient of the toroidal current at the plasma edge induces a strong kink instability. The balance between these two effects leads to an optimization of the current profile and gives rise to a beta limit in the range of $2-4 \%$ for an elongated plasma cross section ${ }^{4,5}$ surrounded by an infinite vacuum.

The optimal beta can be increased if a perfectly conducting wall lies at some distance around the plasma to stabilize surface modes.

The purpose of this letter is to study the critical wall position required to avoid the kink instability. We have chosen one of the worst equilibria with respect to kink behavior, namely the solov'ev equilibrium. ${ }^{6}$ The toroidal wave numbers $N=0,1$, and 2 have heen considered.

This study diso tests the vacuum module implemented in the ERATO. code. $^{7}$ The results of previous computations with both no wall and with a wall tight against the plasma surface ${ }^{8}$ are nicely reproduced. Only a careful treatment of the singularities ${ }^{9}$ linked with the Green's function technique used can lead to such a good agreement. 
For low-N modes $(N=0,1)$ the shell position constraint is very flexible. However, for larger $N$, the wall-plasma distance required can vary between $5 \%$ and $15 \%$ of the plasma radius.

Wall stabilization, supplied by a feedback system acting on the time scale of the field diffusion across the shell, may have to be designed in high beta tokamak experiments $(\beta>5 \%)$.

\section{EQUILIBRIUM PARAMETERS}

We have chosen the Solov'ev equilibrium ${ }^{6}$ given by $\psi(r, z)=$ $\frac{E}{2 q_{0}} \frac{a^{2}}{R^{2}}\left[\frac{r^{2} z^{2}}{E^{2}}+\frac{\left(r^{2}-R^{2}\right)^{2}}{4}\right]$ and characterized by three parameters: the aspect ratio $\mathrm{R} / \mathrm{a}$, the vertical elongation $\mathrm{E}$, and the safety factor on axis $q(0)$. The poloidal beta is equal to 1 and the aspect ratio is kept fixed at 3 ; note that the current is linear in $r$ and that there is a substantial amount of shear since $q\left(\psi_{s}\right) / q_{0}(0)=1.74$. We assume also uniform mass densily $\mu$; the index s refers to the plasma surface.

The wall is defined as

$\rho_{1}(\theta)=\rho_{p}(\theta)[\Lambda+f(\Lambda, \theta)]$

where $\rho_{p}$ and $\rho_{w}$ are the polar radii from the magnetic axis to the wall and the plasma, respectively. The polar angle $\theta$ is defined by the magnetic axis and the midplane of symmetry. $\Lambda$ defines the distance, plasma wall, and $F(\Lambda, \theta)$ equals

$F(\Lambda, \theta)=0$

$$
\Lambda \leq \frac{0.99}{\rho_{p}(\pi)}
$$


$F(\Lambda, \theta)=\left[\frac{0.99}{\rho_{p}(\pi)}-1\right]\left(\sin ^{2} \frac{\theta}{2}-\frac{1}{2} \sin ^{2} \theta\right) \quad . \Lambda>\frac{0.99}{\rho_{p}^{\prime}(\pi)}$

Equation (2) simply means that the inner point of the wall on the midplane of up-down symmetry is kept fixed for $\Lambda>0.99 / \rho_{p}(\pi)$.

The stability analysis is performed with the spectral ERATO code. ${ }^{7}$ Growth rates are normalized with respect to the poloidal Alfvén frequency $\omega_{A}-B_{T} / \sqrt{\rho} q(0) R$ where $R_{T}$ is the toroidal magnctic field on axis.

\section{RESULTS}

\subsection{AXISYMMETRIC MODE}

In Fig. 1, the square of the normalized growth rate of the axisymmetric instability is plotted versus the shell position $\Lambda$. The elongation of the plasma cross section is equal to 2 and the safety factor on the axis is kept fixed at $7 . E=2$ gives an elongated, D-shaped cross section very close to the JET design; the corresponding $\Lambda$ value equals 1.5. Note that the variation of the growth rate is proportional to the volume between the plasma and the wall $1-1 / \Lambda^{3}$. By extrapolation, we determine that the critical value for $\Lambda$ for stability is $\Lambda_{c}=1.8$. Such a big value reflects the strong effect of the wall in stabilizing axisymmetric modes.

\section{2. $\mathrm{N}=1, \mathrm{~N}=2$}

Figure 2 represents the growth rate of the most unstable mode versus $\Lambda$ for toroidal mode numbers $N=1$ and $N=2$. Dashed lines refer to a circular plasma cross section $(E=1)$ and the solid line to an elongated $D$-shape $(E=2)$. On each curve the safety factor is kept fixed. The 
variation is proportional to $1-1 / \Lambda^{2}$ over a wide range of values of $\Lambda$, and both limits $(\Lambda \rightarrow 1, \Lambda \rightarrow \infty)$ are well reproduced. ${ }^{9}$ As previously found there is no internal mode for $N=1, E=1$. In that case the critical value of $\Lambda$ to completely stabilize the external kink is $\Lambda_{c} \approx 1.25$. For other cases we see that the critical value of $\Lambda$ decreases as $N$ increases $\left(\Lambda_{c}=1.11\right.$ for $\left.N=2\right)$; also the wall has to be closer for higher elongations $\left(\Lambda_{c}=1.11\right.$ for $\left.E=2\right)$.

The technological constraints induced by these $\Lambda$ values are severe but do not jeopardize the use of wall stabilization to increase the total average beta. $E=1, q_{0}=1$ correspond to an average beta of $10 \%$.

\section{3. $q_{5}$ Dependence}

We now investigate the variations of the growth rate of the most unstable mode versus $q_{0}$ for different wall locations. Results are shown in Fig. 3. Two important points have to be noted. At high $q_{0}$ the three curves do not tend together as expected for a cylindrical plasma discharge. This phenomenon is due to the toroidal mode coupling. The $M=1$ cylindrical mode is always present, even if $q_{S}=4$ at the plasma surface. For a reasonable wall location, $\Lambda=1.55$, we obtain stable ranges of operation for a high beta tokamak device, for example $0.7 \leq q_{0} \leq 1$ or $q_{0}>1.2$; this latter result is in qualitative agreement with a recent analytical model. ${ }^{10}$ The critical distance of the stabilizing shell is plotted versus $q_{0}$ in Fig. 4. Each oscillation corresponds to an increment of one in the dominant poloidal Fourier component of the mode. 


\section{CONCLUSION}

For a toroidal, low aspect ratio discharge surrounded by an infinite vacuum region, beta limitations imposed by MHD stability considerations lie in the range of $2-3 \%$. In order to increase this value up to $5-10 \%$, other factors such as force-free equilibrium current, cold plasma blanket, or wall stabilization have to be included. We have studied the effect of wall stabilization on a high beta, flat current equilibrium. Parallel computations have shown that this equilibrium is ballooning stable. ${ }^{3}$ For a stabilizing shell at a reasonable distance from the plasma, a range of operation has been found with a corresponding beta value greater than $10 \%$.

\section{ACKNOWLEDGEMENTS}

We are indebted to Drs. G. Bateman and R. A. Dory for many helpful discussions.

Resedrch sponsered jointly by the Swiss National Science Foundation and by the Office of Fusion Energy, U.S. Department of Energy, under contract W-7405-eng-26 with the Union Carbide Corporation. 


\section{REFERENCES}

[1] J. F. Clarke, D. J. Sigmar; Phys. Rev. Lett. 38, 70-74 (1977).

[2] R. A. Dory, Y-K. M. Peng, Nucl. Fusion 17, 21 (1977).

[3]. A. A. Todd et a1., Phys. Rev. Lett. 38, 826-829. (1977), G. Bateman, Y-K. M. Peng, Phys. Rev. Lett. $\underline{38}$, 829-832 (1977), D. Dobrott et al., Phys. Rev. Lett. 39, 943-946 (1977), D. Nelson, private communications.

[4] D. Berger, F. Troyon; R. Gruber, submitted to Phys. Rev. Lett. (1977).

[5] R. A. Dory, D. B. Nelson, Y-K. M. Peng, D. Berger, L. C. Bernard, R. Gruber, F. Troyon (CRPP) VIIIth Europ. Comp. on Comtr. Fusion and Plasma Physics (Prague, 1977).

[6] L. S. Solov'ev, Zh. Eksp. Teor. Fiz. $\underline{53}, 626$ (1967); [Sov. Phys.-JETP 26, $400(1968)]$.

[7] D. Berger, R. Gruber, F. Troyon, 2nd European Conference on Computational Physics, C3, (1976).

[8] D. Berger, L. C. Bernard, R. Gruber, F. Troyon, submitted to Nucl. Fusion.

[9] L. C. Bernard, D. Berger, R. Gruber, F. Troyọn, ZAMP 28, 353 (1977).

[10] 0. P. Pogutse, E. I. Yurchenko, ORNL/TM-4410 by D. J. Sigmar and B. V. Wadde? 1 . 
8

FIGURE CAPTIONS

Fig. 1. Growth rate $\Gamma^{2}$ of the most stable axisymmetric mode versus the shell position $\Lambda . q_{0}=1$.

Fig. 2. Growth rate $\Gamma^{2}$ of the most unstable $N=1$ and $N=2$ modes versus the shell position $\Lambda(-E=2,---E=1)$.

Fig. 3. Plot of the normalized growth rate $\Gamma^{2}$ of the most unstable mode versus $q_{0}$. Four different shell positions $(\Lambda)$ are represented.

Fig. 4. Critical shell position for stability versus $q_{0}$. The dashed region corresponds to the stability requirements $(E=1, N=2)$. 


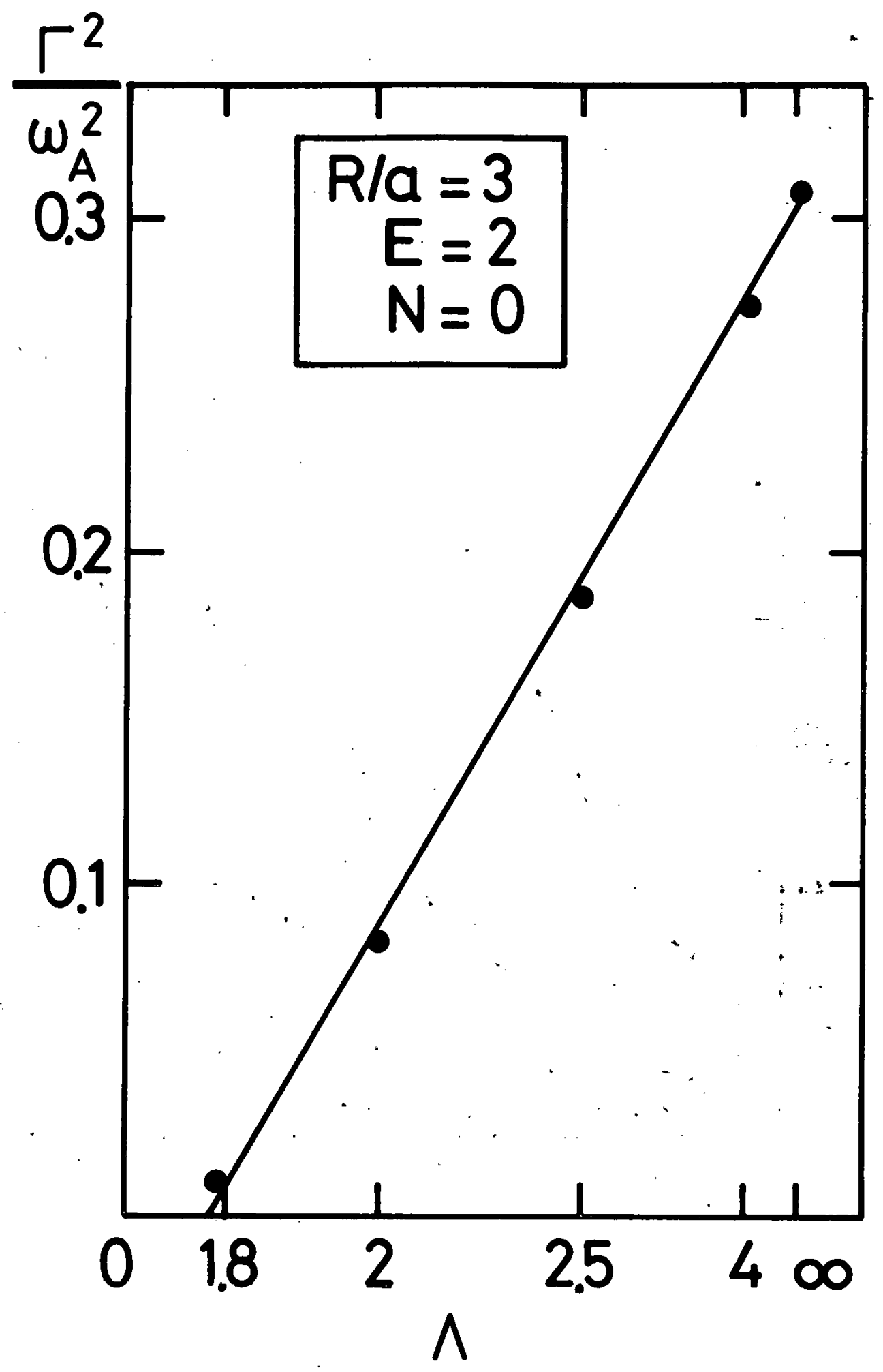

Fig. 1. 


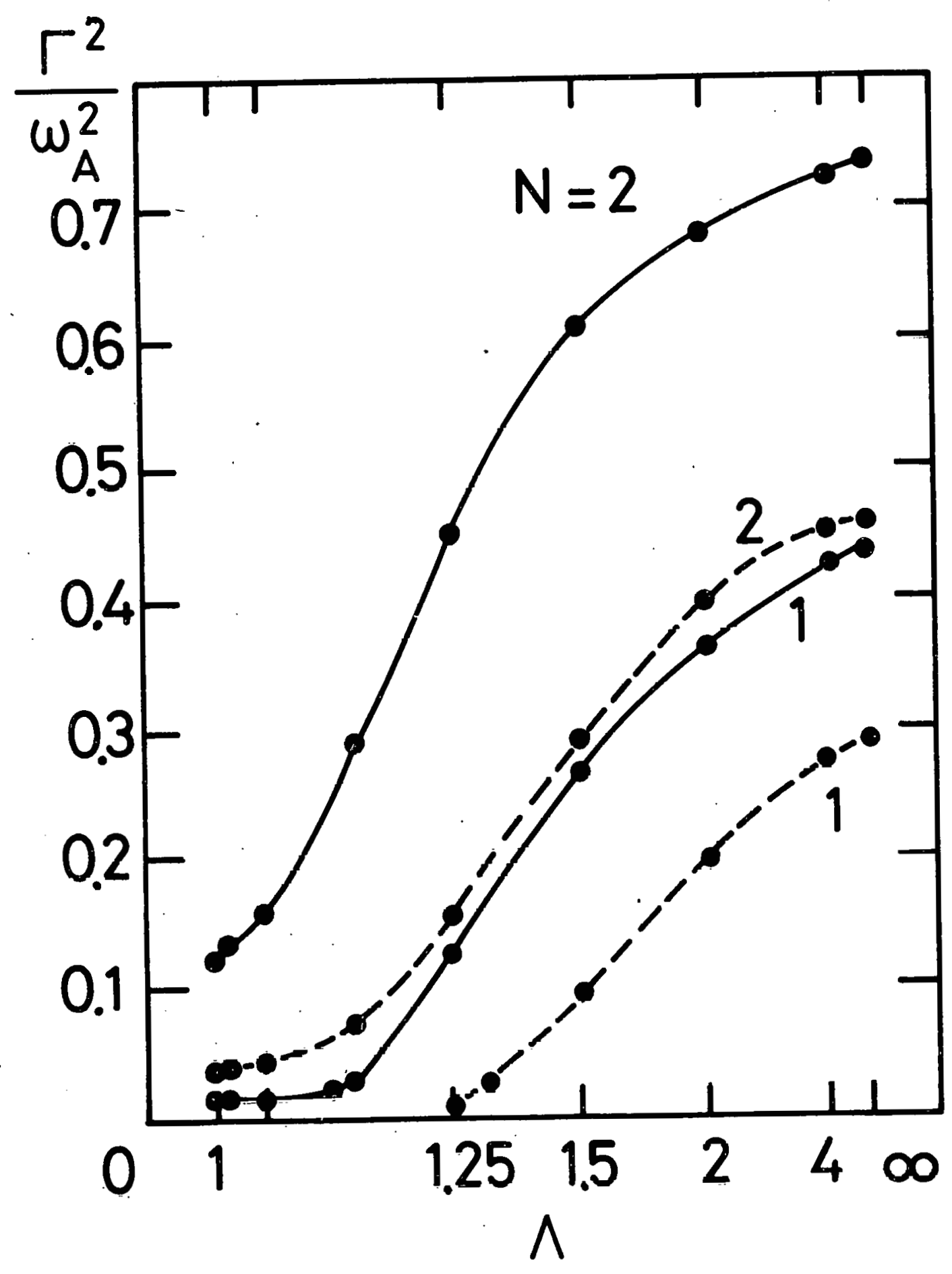

Fig. 2. 


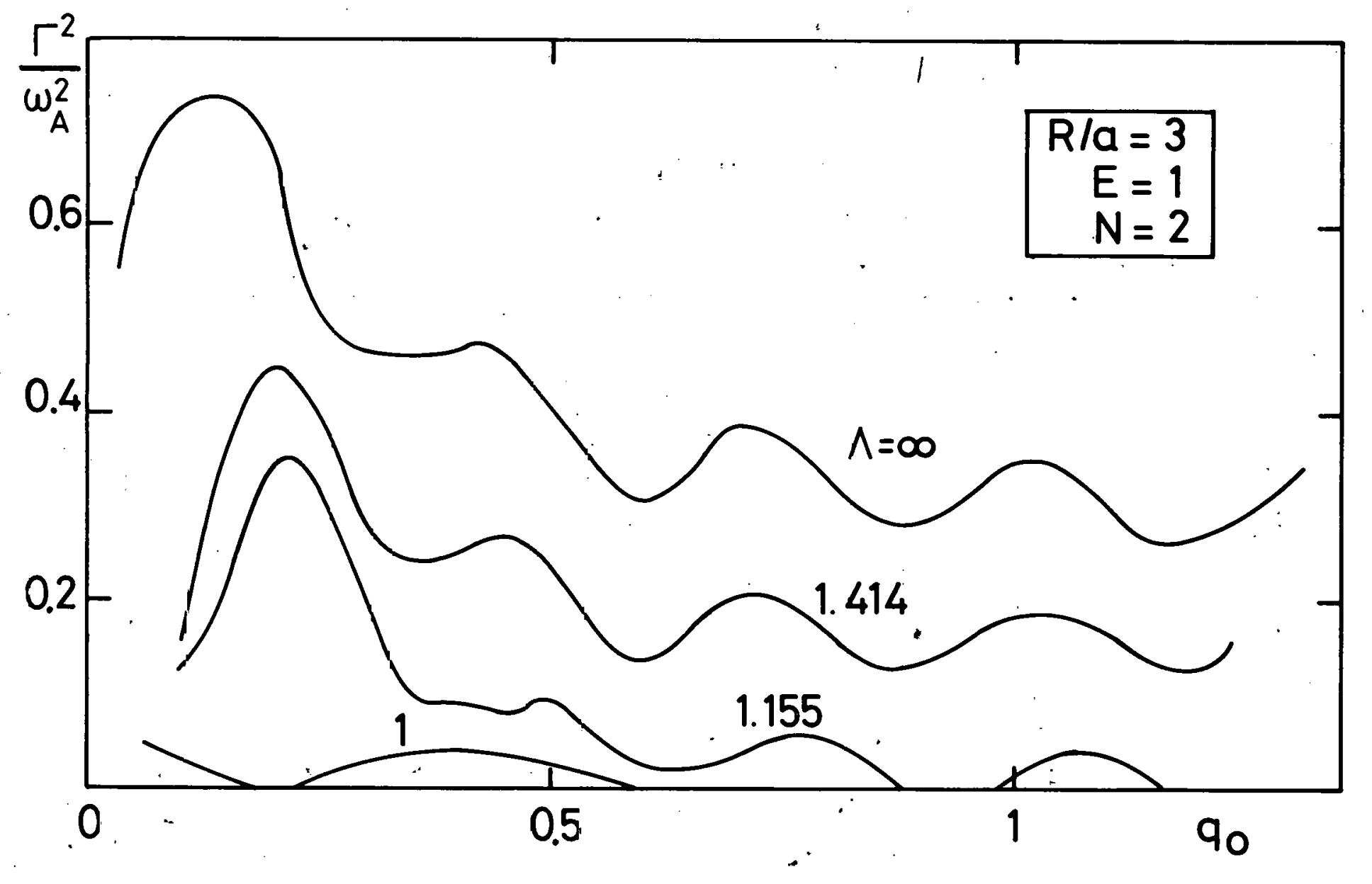

Fig. 3. 


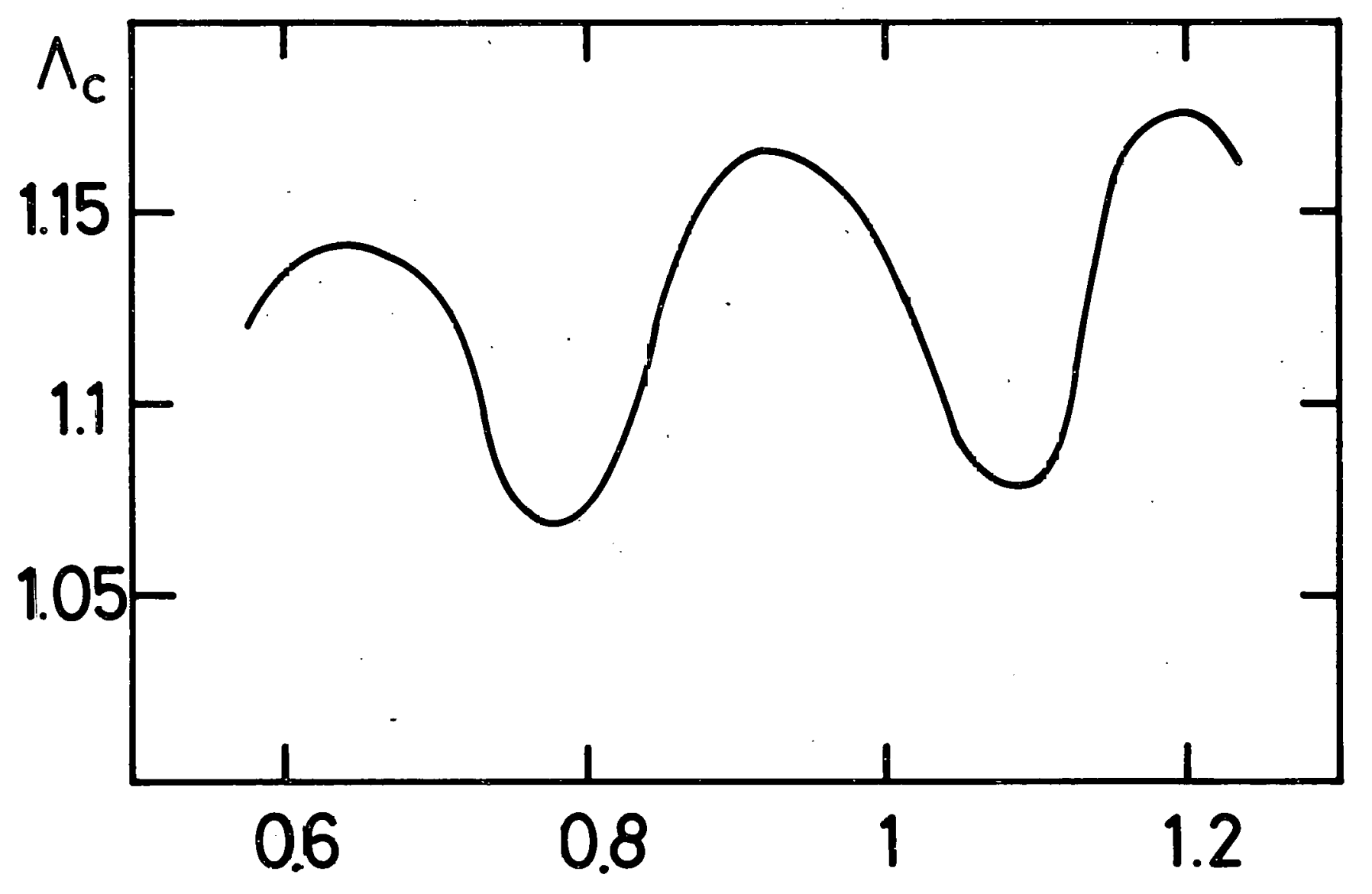

Fig. 4. 
ORNL/TM-6219

Dist. Category UC-20g

\section{INTERNAL DISTRIBUTION}

1. L. A. Berry

2. J. D. Callen

3. R. A. Dandl

4. R. A. Dory

5. G. G. Kelley

6. H. H. Haselton

7. P. N. Haubenreich

8. M. S. Lubell

9. 0. B. Morgan

10. H. Postma

11. M. W. Rosenthal
12. J. Sheffield

13. D. Steiner

14-47. D. Berger

48-49. Laboratory Records Department

50. Laboratory Records, ORNL-RC

51. Document Reference Section

52-53. Central Research Library

54. Fusion Energy Division Library

55. Fusion Energy Division Communications Center

56. ORNL Patent office

\section{EXTERNAL DISTRIBUTION}

57. Bibliothek, Max-Planck Institute für Plasmaphysik, 8046 Garching bei München, Federal Republic of Germany

58. Bibl iotheque, Service du Confinement des Plasmas, C.E.A., B.P. No. 6, 92, Fontenay-aux Roses (Seine), France

59. Lung Cheung, Department of Electronics, University Science Center, The Chinese University of Hong Kong, Shatin, N.T., Hong Kong

60. J. F. Clarke, Office of Fusion Energy, G-234, Department of Energy, Washington, DC 20545

61. R. W. Conn, Fusion Technology Program, Nuclear Engineering Department, University of Wiscurisin, Madison, WI 53706

62. CTR Library, c/o Alan F. Haught, United Technologies Research Laboratory, East Hartford, CT 06108

63. CTR Reading Room, c/o Allan N. Kaufman, Physics Department, University of Cal ifnrnia, Berkeley, CA 94720

64. J. Narl Davidson, School of Nuclear Engineering, Georgiad Institute of Technology, Atlanta, GA 30332

65. Documentation S.I.G.N., Department de la Physique du Plasma et de la Fusion Controlee, Association EURATOM-CEA sur la Fusion, Centre d'Études Nucléaires, B.P. 85, Centre du TRI, 38041 Grenoble, Cedex, France

66. W. R. Ellis, Office of Fusion Energy, G-234, Department of Energy, Washington, DC 20545

67. Harold K. Forsen, Exxon Nuclear Co., Inc., 777 106th Avenue, N.E., C-000777, Bellevue, WA 98009

68. Harold P. Furth, Princeton Plasma Physics Laboratory, Princeton University, Forrestal Campus, P.0. Box 451, Princeton, NJ 08540

69. Roy W. Gould, California Institute of Technology, Mail Stop 116-81, Pasadena, CA 91125

70. Robert. L. Hirsch, Exxon Research and Engineering, P.0. Box 101, Florham Park, NJ 07932 
71. Raymond A. Huse, Manager, Research and Development, Public Service Gas and Electric Company, 80 Park Place, Newark, NJ 07101

72. T. Hsu, Office of Fusion Energy, G-234, Department of Energy, Washington, DC 20545

73. V. E. Ivanov, Physical-Technical Institute of the Ukranian Academy of Sciences, Sukhumi, U.S.S.R.

74. A. Kadish, Office of Fusion Energy, G-234, Department of Energy, Washington, DC 20545

75. L. M. Kovrizhnikh, Lebedev Institute of Physics, Academy of Sciences of the U.S.S.R., Leninsky Prospect 53, Moscow, U.S.S.R.

76. Guy Laval, Groupe de Physique Thérique, Ecole Polytechnique, 97 Palaiseau, Paris, France

77. Library, Centre de Recherches en Physique des Plasma, 21 Avcnue des Bains, 100/, Lausanne, Switzerland

78. Library, Culham Laboratory, United Kingdom, Atomic Energy Authority, Abingdon, Oxon, OX74 3DB, United Kingdom

79: Library, FOM-Institut voor Plasma - Fysica, Rijnhuizen, Jutphaas, Netherlands

80. Library, Institute for Plasma Physics, Nagoya University, Nagoya, Japan 454

81. Library, International Centre for Theoretical Physics, Trieste, Italy

82. Library, Laboratorio Gas Ionizzati, Frascati, Italy

83. Dsumber G. Lominadze, Academy of Sciences of the Georgian S.S.R., 8 Dzerzhinski St., 38004, Tbilisi, U.S.S.R.

84. Oscar P. Manley, Office of Fusion Energy, G-234, Department of Energy, Washington, DC 20545

85. D. G. McAlees, Exxon Nuclear Co., Inc., Research and Technology Laser Enrichment Department, 2955 George Washington Way, Richland, WA 99352

86. J. E. McCune, School of Engineering, Department of Aeronautics and Astronautics, Bldg. 37-391, Massachusetts Institute of Technology, Cambridge, MA 02139

87. Claude Mercier, Service du Theorie des Plasmas, Centre d'Études Nucleaires, Fontenay-aux-Roses (Seine), France.

88. K. G. Muses, Office of Fusion Energy, G-234, Department of Energy, Washington, DC 20545

89. D. Pfirsch, Institute for Plasma Physics, 8046 Garching bei München, Federal Republic of Germany

90. Plasma Physics Group, Department of Engineering Physics, Australian National University, P.0. Box 4, Canberra A.C.T. 2600, Australia

91. Robert E. Price, Office of Fusion Energy, G-234, Department of Energy, Washington, DC 20545

92. A. Rogister, Institute for Plasma Physics, KFA, Postfach 1913, D-5170, Jülich 1, Federal Repub7 ic of Germany

93. W. Sadowski, Office of Fusion Energy, G-234, Department of Energy, Washington, DC 20545

94. V. D. Shafranov, I. V. Kurchatov Institute of Atomic Energy, 46 Ulitsa Kurchatova, P.0. Box 3402, Moscow, U.S.S.R. 
95. Yu. S. Sigov, Institute of Applied Mathematics of the U.S.S.R. Academy of Sciences, Miuskaya, Sq. 4, Moscow A-47, U.S.S.R.

96. W. M. Stacey, Jr., School of Nuclear Engineering, Georgia Institute of Technology, Atlanta, GA 30332

97. J. B. Taylor, Culham Laboratory, U.K. Atomic Energy, Authority, Abingdon, Oxon, OX14 3DB, United Kingdom

98. Thermonuclear Library, Japan Atomic Energy Research Institute, Tokai, Naka, Ibaraki, Japan

99. Francisco Verdaguer, Director, Division of Fusion, Junta de Energia Nuclear, Madrid 3, Spain

100. Director, Research and Technical Support Division, Department of Energy, Oak Ridge Operations, P.0. Box E, Oak Ridge, TN 37830

101-276. Given distribution as shown in TID-4500, Magnetic Fusion Energy (Distribution Category UC-20g, Theoretical Plasma Physics) 